\title{
Equilibrium Relation of Phosphorus, Carbon and Oxygen \\ in Liquid Iron*
}

\author{
By Shiro Ban-ya** and Sachio Matoba***
}

\section{Synopsis}

Two series of different measurements described as follows have been carried out to obtain the fundamental relations of phosphorus, carbon and oxygen in iron at a steelmaking temperature.

In order to know the effect of phosphorus on the activity coefficient of carbon and oxygen in iron, the carbon and oxygen in liquid iron-phosphorus alloys, melted in a magnesia crucible have been equilibrated with a $\mathrm{CO}-\mathrm{CO}_{2}$ gas mixture of a known composition at $1,510^{\circ}, 1,560^{\circ}$ and $1,610^{\circ} \mathrm{C}$. The experiments of this series were carried out under the condition in which the phosphorus in the iron was not eliminated by oxidation in the $0.5 \sim$ $5.5 \% \mathrm{P}$ range. The results obtained are as follows:

(1) The relationships between the activity coefficients of carbon or oxygen and phosphorus in liquid iron:

$$
\begin{aligned}
& e_{\mathrm{C}}^{(\mathrm{P})}=\partial \log f_{\mathrm{C}}^{(\mathrm{P})} / \partial[\% \mathrm{P}]=1,190 / T-0.608 \ldots \ldots<4 \% \mathrm{P} \ldots(1 \mathrm{c}) \\
& \left.e_{\mathrm{P}}^{(\mathrm{C})}=\partial \log f_{\mathrm{P}}^{(\mathrm{C})} / \partial[\% \mathrm{C}]=3,070 / T-1.57 \ldots \text { very dil. sol...(1 } f\right) \\
& e_{\mathrm{O}}^{(\mathrm{P})}=\partial \log f_{\mathrm{O}}^{(\mathrm{P})} / \partial[\% \mathrm{P}]=+0.006 \ldots \ldots \ldots \ldots \ldots<5 \% \mathrm{P} \ldots(2 \mathrm{c})
\end{aligned}
$$

(2) The products of carbon and oxygen contents in liquid iron decrease with increasing phosphorus content.

Equilibrium of phosphorus-carbon-oxygen in liquid iron in contact with a mixture of solid calcium phosphate and calcium oxide was studied under a controlled $\mathrm{CO}-\mathrm{CO}_{2}$ gas mixture atmosphere in the $0.03 \sim 1.2 \%$ phosphorus range in liquid iron at $1530^{\circ}, 1560^{\circ}$, and $1585^{\circ} \mathrm{C}$. It was found in these experiments that the stable phase of calcium phosphate is tetracalcium phosphate, $4 \mathrm{CaO} \cdot \mathrm{P}_{2} \mathrm{O}_{5}$, in the presence of free lime. The results obtained are summarized as follows:

$$
\begin{aligned}
& 2 \underline{\mathrm{P}}+5 \mathrm{CO}_{2}+4 \mathrm{CaO}(\mathrm{S})=5 \mathrm{CO}+\mathrm{Ca}_{4} \mathrm{P}_{2} \mathrm{O}_{9}(\mathrm{~S}) \\
& \log K_{4}\left(=P_{\mathrm{co}}^{5} / P_{\mathrm{CO}_{2}}^{5} \cdot a_{\mathrm{p}}^{2}\right)=32,070 / T-7.960 \\
& \Delta F_{4}^{\circ}=-146,700+36.42 T \\
& 2 \underline{\mathrm{P}}+5 \mathrm{CO}+4 \mathrm{CaO}(\mathrm{S})=5 \underline{\mathrm{C}}+\mathrm{Ca}_{4} \mathrm{P}_{2} \mathrm{O}_{9}(\mathrm{~S}) \\
& \log K_{5}\left(=a_{\mathrm{c}}^{5} / a_{\mathrm{p}}^{2} \cdot P_{\mathrm{co}}^{5}\right)=69,860 / T-41.79 \\
& \Delta F_{5}^{\circ}=-319,600+191.2 T \\
& 2 \underline{\mathrm{P}}+5 \underline{\mathrm{O}}+4 \mathrm{CaO}(\mathrm{S})=\mathrm{Ca}_{4} \mathrm{P}_{2} \mathrm{O}_{9}(\mathrm{~S}) \\
& \log K_{6}\left(=1 / a_{\mathrm{p}}^{2} \cdot a_{\mathrm{o}}^{5}\right)=75,660 / T-31.77 \\
& \Delta F_{6}^{\circ}=-346,100+145.3 T
\end{aligned}
$$

\section{Introduction}

The reaction of phosphorus elimination in the basic steelmaking process is of great importance because phosphorus is a harmful element that is spontaneously dissolved in iron. Many investigations have been carried out in order to obtain a better phosphorus content control in finished steels.

The phosphorus-elimination reaction and its equilibrium constant in the basic steelmaking process may be written as follows:

$$
\begin{gathered}
2 \underline{\mathrm{P}}+5 \underline{\mathrm{O}}+4(\mathrm{CaO})=\left(4 \mathrm{CaO} \cdot \mathrm{P}_{2} \mathrm{O}_{5}\right) \\
K=a_{4 \mathrm{CaO} \cdot \mathrm{P}_{2} \mathrm{O}_{5}} / a_{\mathrm{P}}^{2} \cdot a_{\mathrm{O}}^{5} \cdot a_{\mathrm{CaO}}^{4}
\end{gathered}
$$

But, as a result, there has been little agreement in the experimental results obtained by many investigators $^{1) \sim 3)}$, and the main reason for the discrepancies has arisen from lack of fundamental knowledge of the physico-chemical behavior for each of the components in molten iron and the slag phase concerned with phosphorus-elimination reaction. In recent years, two very interesting works on phosphorus reaction have been reported by J. B. Bookey, F. D. Richardson \& A. J. E. Welch ${ }^{4}$, who studied phosphorus-oxygen equilibrium in liquid iron, and by G. Urbain ${ }^{5)}$, who measured the phosphorus distribution between molten iron and silver. But, at the present stage in the developments of new steelmaking methods, their results are not yet sufficient in understanding the fundamental quantitative character for phosphorus elimination in the steelmaking process. Especially, in such new pneumatic steelmaking processes as the LD, the Kaldo and the Rotor process, it is necessary to eliminate the phosphorus in the iron rapidly within a limited concentration before finishing the decarbonizing reaction in the refining process. The equilibrium relation in phosphorus, carbon and oxygen in iron is very interesting. Therefore, in a series of equilibrium measurements of the Fe- - $-\underline{O}$ system carried out by the present authors ${ }^{6)}$, attempts were made to obtain a fundamental relation of phosphorus, carbon and oxygen in iron in equilibrium with $\mathrm{CO}-\mathrm{CO}_{2}$ gas mixture at a steelmaking temperature.

\section{Chemical Reaction and Reaction Products}

In the experiment described in this paper, two series of different measurements were carried out. In the first series, the iron-phosphorus alloys were melted in a magnesia crucible, and the $\mathrm{CO}-\mathrm{CO}_{2}$ gas mixture equilibrium of known composition was measured with carbon and oxygen in iron-phosphorus alloys under the experimental condition that phosphorus in ironphosphorus alloys cannot be removed with an oxidizing reaction. Therefore the equilibrium equations in this measurement series are shown by the same following equations as in the pure Fe- $\underline{\mathrm{C}}-\underline{\mathrm{O}}$ system without phosphorus:

$$
\begin{aligned}
& \underline{\mathrm{C}}+\mathrm{CO}_{2}=2 \mathrm{CO} \\
& \underline{\mathrm{O}}+\mathrm{CO}=\mathrm{CO}_{2} \\
& \underline{\mathrm{C}}+\underline{\mathrm{O}}=\mathrm{CO}
\end{aligned}
$$

* Lecture delivered before the 63rd Grand Lecture Meeting of The Iron \& Steel Institute of Japan in April 1962 in Tokyo. Japanese text was received on July 31st, 1962 and printed in Tetsu-to-Hagané (Journal, Iron \& Steel Institute, Japan), 49 (1963), 4, 666$672 ; 5,753-758$.

** Dr. Eng., Assistant Prof., Dept. of Metallurgy, Faculty of Eng., Tohoku University.

*** Dr. Eng., Honorary Prof., Dept. of Metallurgy, Faculty of Eng., Tohoku University. 
The results obtained show the effect of phosphorus on the activity coefficient of carbon and oxygen in molten iron.

The second series of measurement employed the lime crucible, the inner surface of which is in contact with liquid iron and is coated with a mixture of solid calcium phosphate and calcium oxide. The equilibrium of phosphorus-carbon-oxygen in liquid iron in contact with the solid lime-calcium phosphate phase was studied under a controlled gas atmosphere of $\mathrm{CO}-\mathrm{CO}_{2}$ gas mixture. The results obtained were used for the corresponding concentration of phosphorus, carbon and oxygen in iron, in equilibrium with solid lime and calcium phosphate at the steelmaking temperature. In order to complete the understanding of equilibrium relation in this series, it is necessary to confirm the stability of calcium phosphate in contact with pure lime at the steelmaking temperature. Up to this time, there have been two opinions concerning the stable phase of calcium phosphate in phosphorus elimination in the basic steelmaking process. One is tricalcium phosphate, $3 \mathrm{CaO} \cdot \mathrm{P}_{2} \mathrm{O}_{5}$, and the other is tetracalcium phosphate, $4 \mathrm{CaO} \cdot \mathrm{P}_{2} \mathrm{O}_{5}$. X-ray analysis of the inner surface of the crucible which was in contact with liquid iron during the equilibrium measurement was examined in order to accertain the correct equilibrium phase of calcium phosphate. The observed results of the X-ray photograph showed clearly six lines in agreement with the data on tetracalcium phosphate reported by M. A. Bredig, H. H. Frank and H. Füldner ${ }^{7}$. In this experiment it was confirmed that the inner surface of the lime crucible in contact with liquid iron consists of a mixture of pure lime and tetracalcium phosphate. The same result has also been reported by J. B. Bookey, F. D. Richardson and A. J. E. Welch ${ }^{4)}$.

The phase diagram for the $\mathrm{CaO}-\mathrm{P}_{2} \mathrm{O}_{5}$ system also indicates that the stable phase of calcium phosphate in the presence of free lime and under $1,600^{\circ} \mathrm{C}$ is tetracalcium phosphate. They have little mutual solubility, so the activity of lime and tetracalcium phosphate can be combined.

According to the phase rule, components are five, phases are four, and freedom is three. Consequently, under the constant temperature and pressure of this system, the composition of the metal is uniquely determined by the composition of the gaseous phase in equilibrium. Equilibrium equations and equilibrium constants in this system may be written by the following equations:

$$
\begin{aligned}
& 2 \underline{\mathrm{P}}+5 \mathrm{CO}_{2}+4 \mathrm{CaO}(\mathrm{S})=5 \mathrm{CO}+\mathrm{Ca}_{4} \mathrm{P}_{2} \mathrm{O}_{9}(\mathrm{~S}) \ldots \ldots(4) \\
& K_{4}=P_{\mathrm{CO}}^{5} / P_{\mathrm{CO}}^{5} \cdot a_{\mathrm{P}}^{2} \\
& 2 \underline{\mathrm{P}}+5 \mathrm{CO}+4 \mathrm{CaO}(\mathrm{S})=5 \underline{\mathrm{C}}+\mathrm{Ca}_{4} \mathrm{P}_{2} \mathrm{O}_{9}(\mathrm{~S})
\end{aligned}
$$

$$
\begin{array}{r}
K_{5}=a_{\mathrm{C}}^{5} / P_{\mathrm{CO}}^{5} \cdot a_{\mathrm{P}}^{2} \\
2 \underline{\mathrm{P}}+5 \underline{\mathrm{O}}+4 \mathrm{CaO}(\mathrm{S})=\mathrm{Ca}_{4} \mathrm{P}_{2} \mathrm{O}_{9}(\mathrm{~S}) \\
K_{6}=1 / a_{\mathrm{P}}^{2} \cdot a_{\mathrm{O}}^{5} \ldots \ldots \ldots \ldots \ldots \ldots \ldots \ldots \ldots \ldots \ldots \ldots \ldots \ldots
\end{array}
$$

\section{Experimental Procedure}

The experimental technique and equipment will be described briefly as they have been discussed in considerable detail in the previous paper ${ }^{6}$.

\section{Apparatus and Preparation of the Gas Mixture}

Carbon dioxide gas taken from the cylinder and carbon monoxide gas produced by the reaction of formic acid and hot sulphuric acid, are purified by passing through several purification traps. The flow rate of each gas was controlled by adjusting its pressure drop across a capillary flow-meter. In order to get a desirable gas ratio $P_{\mathrm{CO}} / P_{\mathrm{CO}}$, the flow rate of carbon monoxide gas was always kept constant at $200 \mathrm{ml} / \mathrm{min}$, to which an arbitrary amount of carbon dioxide gas was constantly mixed through the modified microflow-meter, and then the mixed gas was streamed into the reaction tube. An analysis of the gas composition in the gas mixture was determined volumetrically under low pressure by using liquid air. The reaction chamber is a glazed silica tube with an inside diameter of $38 \mathrm{~mm}$ and is $50 \mathrm{~cm}$ long. The metal was heated by a high frequency induction unit. The temperature of molten iron was measured by an optical pyrometer. The calibrations for an optical pyrometer were made by two methods, by observing the melting point of the electrolytic iron in a hydrogen gas atmosphere and checking against the calibrated $\mathrm{Pt}-\mathrm{Pt} \cdot \mathrm{Rh}$ thermocouple.

\section{Charge and Crucible}

The charge of a given composition consists of electrolytic iron, iron-carbon and iron-phosphorus master alloy, and the total weight of one charge is $20-30 \mathrm{~g}$. Two kinds of master alloys were previously prepared with an electrolytic iron and its pure element in our laboratory. For example, iron-phosphorus master alloy containing about $17 \%$ of the phosphorus was made by adding red phosphorus to liquid iron in an argon gas atmosphere containing 2-3\% carbon monoxide gas.

The crucibles with an i.d. of $15 \mathrm{~mm}$ and a height of $30 \mathrm{~mm}$ used in this equilibrium measurement were made of magnesia or lime, and the inner surface of the lime crucibles was coated with a mixture of lime and calcium phosphate. The material in the lime crucible was prepared by heating the chemically pure calcium carbonate with silica and grinding under 60 mesh. The undersized lime powder was pressed without any binder in a crucible mold made of graphite 
and was sintered for $1-2 \mathrm{hr}$. at $1,500^{\circ}-1,600^{\circ} \mathrm{C}$ by induction heating. The sintered lime crucible was removed from the graphite mold and was burnt in the air at about $900^{\circ} \mathrm{C}$ after coating the inner surface of the crucible with about $0.25 \mathrm{~g}$ of di-ammonium hydrogen phosphate powder. A crucible prepared by this method contains several kinds of calcium phosphate, but it has been ascertained by X-ray analysis that all of them change to tetracalcium phosphate during the hours of equilibrium measurement.

\section{Experimental Procedure}

The charge of known composition in a crucible was set into the reaction tube. After other gasses in the reaction tube were flushed out with a $\mathrm{CO}-\mathrm{CO}_{2}$ gas mixture of desired composition for about $30 \mathrm{~min}$., the induction unit was turned on and the high frequency input was then adjusted to bring the metal to an experimental temperature within $15 \mathrm{~min}$. Under such a steady condition, all runs were finally kept at a constant temperature within the $\pm 10^{\circ} \mathrm{C}$ range for about $4 \mathrm{hr}$, until equilibrium was attained.

At the end of the run a sample to determine the equilibrium composition in the metal was taken, by sucking the melt with a silica tube of about $3 \mathrm{~mm}$ bore or by quenching the whole liquid iron instantaneously. It was analysed for phosphorus, carbon and oxygen.

\section{Analytical Method of Equilibrium Sample}

The suction sample in the silica tube was polished with a fine emery cloth and was then used as an analytical sample. The iron ingot in the quenching sample was cut vertically into four equal pieces in order to prevent the segregation of dissolved elements in the iron ingot, and two pieces were used for the determination of oxygen in iron, the others for phosphorus and carbon.

The phosphorus content of the samples was estimated gravitimetrically by weighing phosphorus molybdic anhydride, $\mathrm{P}_{2} \mathrm{O}_{5} \cdot 24 \mathrm{MoO}_{3}$, and an analysis for carbon was carried out by a combustion method. For a determination of the oxygen content the vacuum fusion method was applied and the reproducibility of oxygen analysis was generally within $\pm(0.006 \times[\%$ O $]$ $+0.0002)[\% \underline{\mathrm{O}}]$.

\section{Experimental Results and Its Discussion}

1. Effect of Phosphorus on the Activity Coefficient of Carbon and Oxygen in Liquid Iron

During the first part of this work, in order to obtain the effect of phosphorus on the activity coefficient of carbon and oxygen in liquid iron, the equilibrium of $\mathrm{CO}-\mathrm{CO}_{2}$ gas mixture with carbon and oxygen in liquid iron-phosphorus alloys was studied. This covered 0.27 to $0.5 \%$ carbon, 0.5 to $5.5 \%$ phos- phorus, with the gas ratio, $P_{\mathrm{CO}}^{2} / P_{\mathrm{CO}_{2}}$, from 254 to 288 , and at each of the following temperatures $1,510^{\circ}, 1,560^{\circ}$, and $1,610^{\circ} \mathrm{C}$. Under such experimental conditions, the phosphorus dissolved in iron was not eliminated by the oxidizing reaction with the gas phase. In the initial and final phosphorus content the melting process was kept to a constant level within the analytical error range, and a magnesia crucible was used; the crucible material being neutral for this chemical reaction. Therefore, as mentioned above, its equilibrium equations are written by equations (1), (2) and (3) shown in the foregoing section, and the effect of phosphorus on the activity coefficient of carbon and oxygen in iron was evaluated by combining the change in the apparent equilibrium constant in equations (1), (2) and (3) with the data of pure Fe- - - O system shown in the authors' previous report ${ }^{6)}$.

Four hours were enough to attain equilibrium in this series of measurements. After the attainment of equilibrium, the sample for determining the corresponding equilibrium composition in liquid iron was taken by withdrawing the metal with a silica tube or by quenching the whole liquid instantaneously at the same time the frequency current of the furnace was being turned off. In comparing the analytical results of both sampling methods, the analytical results of the oxygen content for withdrawing the sample with a silica tube showed a better reproducibility than the other method. However, the oxygen content of the equilibrium sample in this experimental range was so low that $0.004-0.006 \%$ of oxygen in comparison with the reproducibility of oxygen determination, $\pm 0.0005 \% \underline{O}$, was unsatisfactory for the effect of phosphorus on the activity coefficient of oxygen in iron. For the phosphorus and carbon content in iron with the exception of oxygen, a difference in the analytical results for both sampling methods was not found.

i. Effect of Phosphorus on the Activity Coefficient of Carbon in Iron

The equilibrium relation of $\mathrm{CO}-\mathrm{CO}_{2}$ gas mixture with carbon in iron is shown by the following equation (1). If the apparent equilibrium constant of equation (1) observed in any given ternary solution is expressed by double prime $K^{\prime \prime}$, and the activity or activity coefficient of carbon referring to an infinitely dilute solution for a standard state is denoted by $a_{\mathrm{C}}$ or $f_{\mathrm{C}}$ respectively, the following relation is given:

$$
\begin{array}{r}
\underline{\mathrm{C}}+\mathrm{CO}_{2}=2 \mathrm{CO} \ldots \ldots \ldots \ldots \ldots \ldots \ldots \ldots \ldots \ldots \ldots \ldots \ldots \ldots \ldots \ldots \ldots \ldots \ldots \ldots \ldots \ldots \ldots \ldots \ldots \ldots \\
K_{1}^{\prime \prime}=P_{\mathrm{CO}}^{2} / P_{\mathrm{CO}_{2}}[\% \mathrm{C}] \\
\log a_{\mathrm{C}}=\log [\% \mathrm{C}]+\log f_{\mathrm{C}}^{(0)}+\log f_{\mathrm{C}}^{(\mathrm{C})}+\log f_{\mathrm{C}}^{(\mathrm{P})}
\end{array}
$$


In this paper $f_{i}^{(j)}$ denotes the effect of dissolved constituents $j$ on the activity coefficient of component $i$ in liquid iron.

In Fig. 1, observed values of $\log K_{1}^{\prime \prime}$ at each experimental temperature are plotted against the weight percentage of phosphorus in iron. As shown in Fig. 1, the values of $\log K_{1}^{\prime \prime}$ increase linearly with increasing phosphorus content in iron up to about $4 \%$ phosphorus and this tendency is more noticeable at lower temperatures. In such a low oxygen potential as in this measurement, the oxygen content in iron is so low that the effect of oxygen on the activity coefficient of carbon in iron may be negligible in comparison with the experimental error of $\log K_{1}^{\prime \prime}$. Therefore, from the data in Fig. 1, it is expected that the activity coefficient of carbon increases with increasing phosphorus content in iron and varies with the temperature. In Fig. 2, the activity coefficient of carbon in iron calculated from equation (1b) by combining the observed values of $\log K_{1}^{\prime \prime}$ with the pure Fe- $\underline{\underline{C}}-\underline{\mathrm{O}}$ system's data reported in the previous paper ${ }^{6)}$ is plotted against the weight percent of phosphorus in iron. The slopes of the lines in Fig. 2 represent the values of the interaction parameter, $\partial$ long $f_{\mathrm{C}}^{(\mathrm{P})} / \hat{\partial}[\% \mathrm{P}]$ which shall be designated here by $e_{\mathrm{C}}^{(\mathrm{P})}$, and it may be expressed as follows:

$e_{\mathrm{C}}^{(\mathrm{P})}=\partial \log f_{\mathrm{C}}^{(\mathrm{P})} / \partial[\% \mathrm{P}]=1.190 / T-0.608 \ldots<4 \% \mathrm{P} \ldots(1 \mathrm{c})$

The relation of equation (1c) being recalculated to a mol fraction of phosphorus in iron, the following equation is given.

$$
\partial \log f_{\mathrm{C}}^{(\mathrm{P})} / \partial \mathcal{N}_{\mathrm{P}}=66,500 / T-33.6 \ldots \ldots<0.007 \mathcal{N} \mathrm{P} \ldots
$$

For the limiting case of a solution which is infinitely

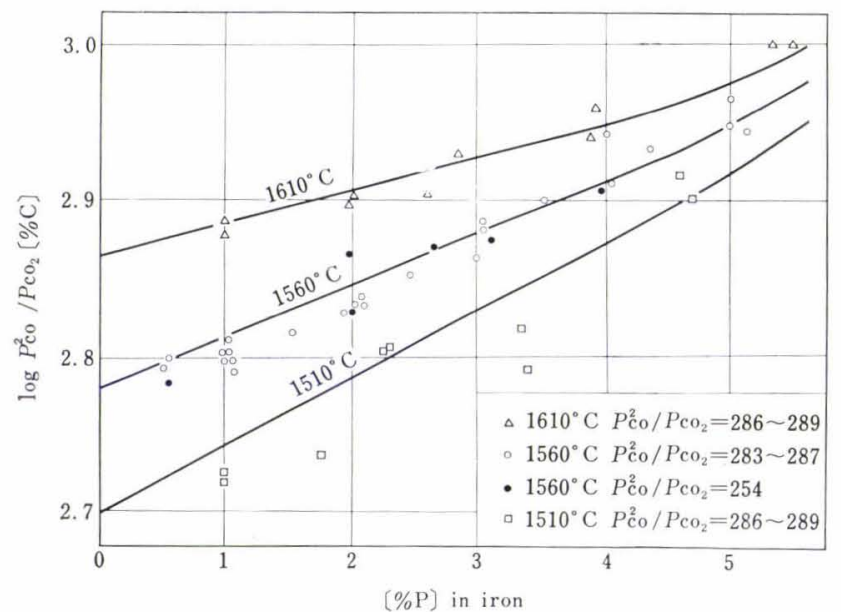

Fig. 1. Effect of phosphorus concentration on $\log K_{1}^{\prime \prime}\left(=P_{\mathrm{CO}}^{2} / P_{\mathrm{CO}_{2}}[\% \mathrm{C}]\right)$ dilute with respect to a multi-components solution, C. Wagner ${ }^{8)}$ has introduced the following relation:

$$
\varepsilon_{\mathrm{C}}^{(\mathrm{P})}=\partial \operatorname{In} f_{\mathrm{C}} / \partial \mathcal{N}_{\mathrm{P}} \quad \varepsilon_{\mathrm{C}}^{(\mathrm{P})} \fallingdotseq \varepsilon_{\mathrm{P}}^{(\mathrm{C})}
$$

Therefore the effect of carbon on the activity coefficient of phosphorus in iron is approximately obtained as follows:

$$
e_{\mathrm{P}}^{(\mathrm{C})}=\partial \log f_{\mathrm{P}}^{(\mathrm{C})} / \partial[\% \mathrm{C}]=3,070 / T-1.57
$$

The results obtained with the above-mentioned relation are summarized as follows at each temperature.

\begin{tabular}{c|c|c|c} 
& $\partial \log f_{\mathrm{c}}^{(\mathrm{p})} / \hat{\partial} \mathcal{N}_{\mathrm{p}}=\hat{\partial} \log f_{\mathrm{p}}^{(\mathrm{e})} / \partial \mathcal{N}_{\mathrm{c}}$ & $e_{\mathrm{c}}^{(\mathrm{p})}$ & $e_{\mathrm{p}}^{(\mathrm{c})}$ \\
\hline $1510^{\circ} \mathrm{C}$ & 3.70 & 0.059 & 0.152 \\
\hline $1560^{\circ} \mathrm{C}$ & 2.68 & 0.041 & 0.105 \\
\hline $1610^{\circ} \mathrm{C}$ & 1.72 & 0.024 & 0.060
\end{tabular}

ii. Effect of Phosphorus on the Activity Coefficient of Oxygen in Iron

The equilibrium relation of $\mathrm{CO}-\mathrm{CO}_{2}$ gas mixture with oxygen in liquid iron is shown by the following relation.

$$
\begin{array}{r}
\mathrm{O}+\mathrm{CO}=\mathrm{CO}_{2} \ldots \ldots \ldots \ldots \ldots \ldots \ldots \ldots \ldots \ldots \ldots \ldots \ldots \ldots \ldots \ldots \ldots \ldots \ldots \ldots \ldots \ldots \\
K_{2}^{\prime \prime}=P_{\mathrm{CO}_{2} /} / P_{\mathrm{CO}}[\% \mathrm{O}] \\
\log a_{0}=\log [\% \mathrm{O}]+\log f_{\mathrm{O}}^{(\mathrm{O})}+\log f_{\mathrm{O}}^{(\mathrm{C})}+\log f_{\mathrm{O}}^{(\mathrm{P})}
\end{array}
$$

In Fig. 3, the observed apparent equilibrium constant of equation (2), $\log K_{2}^{\prime \prime}$, is plotted against the weight percent of phosphorus in iron. Since the oxygen content of iron in this measurement is very low in comparison with the reproducibility of oxygen analysis in the vacuum fusion method, observed values in Fig. 3 are somewhat scattered, but tend to increase

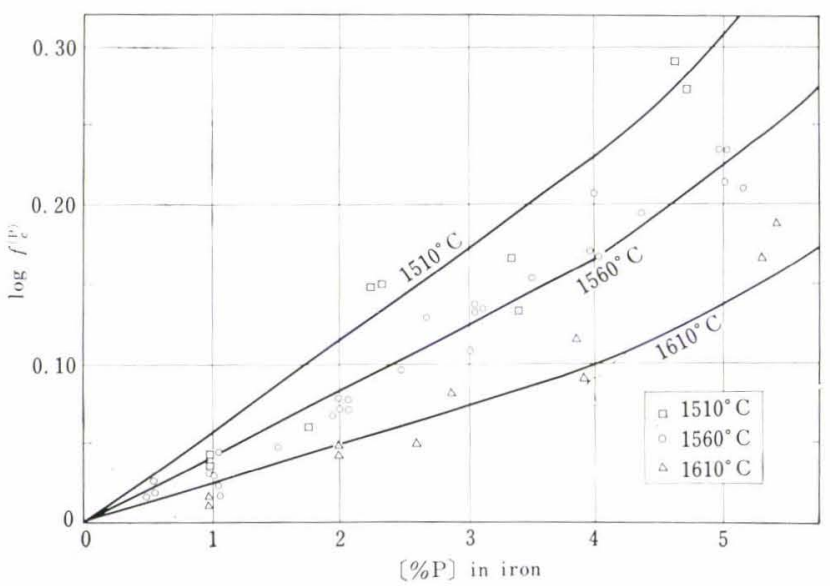

Fig. 2. Effect of phosphorus on activity coefficient of carbon in iron 
linearly with the phosphorus content in iron. In Fig. 4 , the activity coefficient of oxygen in iron computed from equation (2b) by the same method as the foregoing section, shows the phosphorus concentration in iron. Because of the low level of oxygen concentration in iron, present study is inadequate for accurate estimates of interaction parameter for oxygen and phosphorus, but results obtained are shown by the following equation:

$$
e_{\mathrm{O}}^{(\mathrm{P})}=\partial \log f_{\mathrm{O}}^{(\mathrm{P})} / \partial[\% \mathrm{P}]=+0.006 \ldots<5 \% \mathrm{P}
$$

From previous papers on the interaction parameter of oxygen and phosphorus obtained from the equilibrium data for the reaction, $\mathrm{H}_{2}+\mathrm{O}=\mathrm{H}_{2} \mathrm{O}, \mathrm{J}$. Pearson \& E. T. Turkdogan ${ }^{9)}$ gave the value -0.032 , and N. P. Levents \& A. M. Samarin ${ }^{10}-0.044$, while D. Dutilloy \& J. Chipman ${ }^{11)}+0.07$, and K. Sambongi \& H. Koizumi $^{12)}+0.05$, and these results are in disagreement. Authors' work also is not always enough to be reliable, but it has been ascertained that the effect of phosphorus on the activity coefficient of oxygen in iron indicates a positive value and its effect is not great.

iii. Equilibrium of Carbon and Oxygen in Liquid Iron-Phosphorus Alloy

$$
\begin{aligned}
& \underline{\mathrm{C}}+\underline{\mathrm{O}}=\mathrm{CO} \\
& K_{3}^{\prime \prime}=P_{\mathrm{Co}} /[\% \mathrm{C}] \cdot[\% \mathrm{O}] \\
& m^{\prime \prime}=[\% \mathrm{C}][\% \mathrm{O}]
\end{aligned}
$$

As mentioned above, the phosphorus dissolved in iron has a positive effect on the activity coefficient of carbon and oxygen in iron, so it is expected that with an increasing phosphorus content the product decreases. The results obtained for the product of carbon and oxygen are shown in Fig. 5. Its value, $m^{\prime \prime}$ is also calculated by using the equations (1c) and (2c), but, for the empirical formula, the following result is obtained as a function of the phosphorus concentration:

$$
m^{\prime \prime}(=[\% \mathrm{C}] \cdot[\% \mathrm{O}])=\mathrm{m}^{\prime}-0.00026[\% \mathrm{P}] \ldots<5 \% \mathrm{P} \ldots(3 \mathrm{c})
$$

where $m^{\prime}$ is the product of carbon and oxygen in the pure Fe- $-\underline{\mathrm{C}}$ - system without phosphorus.

Thus, it has been confirmed that the product of carbon and oxygen in iron decreases with an increasing phosphorus content in iron.

\section{Equilibrium of Phosphorus, Carbon and Oxygen in Liquid Iron}

In the second series of measurements, in order to know the fundamental relation for phosphorus, carbon and oxygen in liquid iron at a steelmaking temperature, the equilibrium of $\mathrm{CO}-\mathrm{CO}_{2}$ gas mixture of known composition with phosphorus-carbon-oxygen in liquid iron was measured. It was in contact with a mixture of solid tetracalcium phosphate and calcium oxide in the $0.03 \%$ to $1.2 \%$ phosphorus range, with a gas ratio, $P_{\mathrm{CO}} / P_{\mathrm{CO}}$, from 21 to 80 , and at each of the three temperatures, $1530^{\circ}, 1560^{\circ}$ and $1585^{\circ} \mathrm{C}$.

It was recognized by the preliminary experiment that the reaction rate of phosphorus transfer between the melt and the crucible was comparatively rapid. However, in the solid phase chemical reaction the

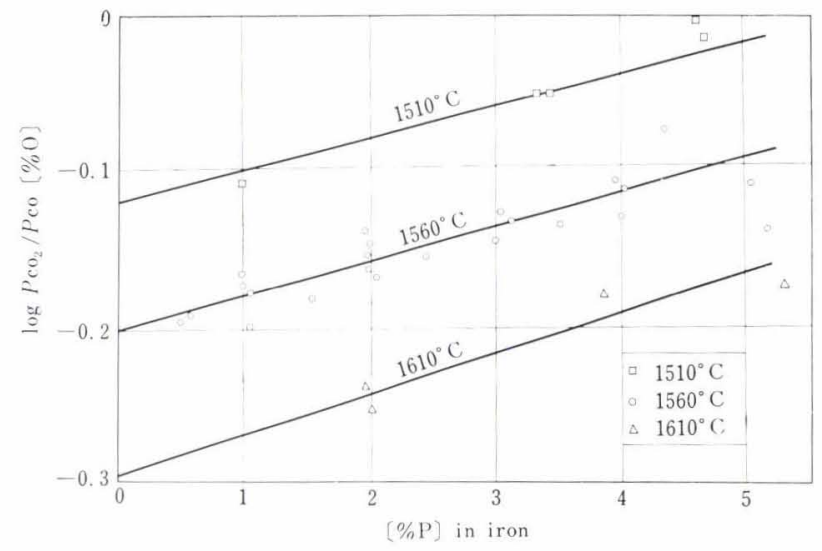

Fig. 3. Effect of phosphorus on $\log K_{2}^{\prime \prime}\left(=P_{\mathrm{CO}_{2}} / P_{\mathrm{CO}}[\% \mathrm{O}]\right)$

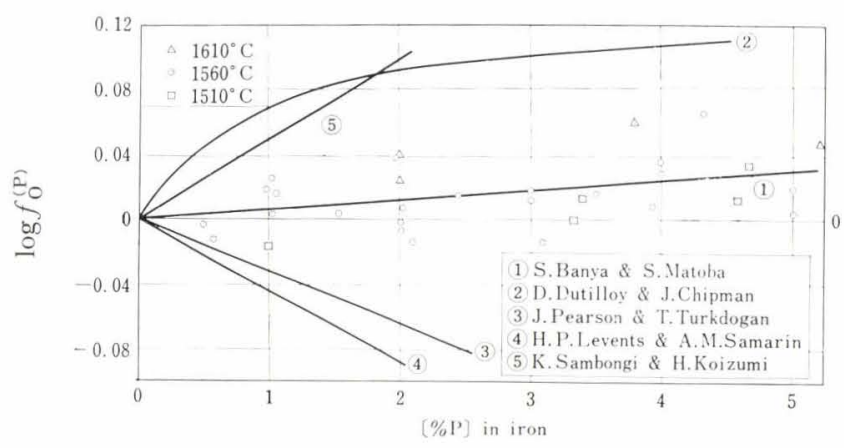

Fig. 4. Effect of phosphorus on activity coefficient of oxygen in iron

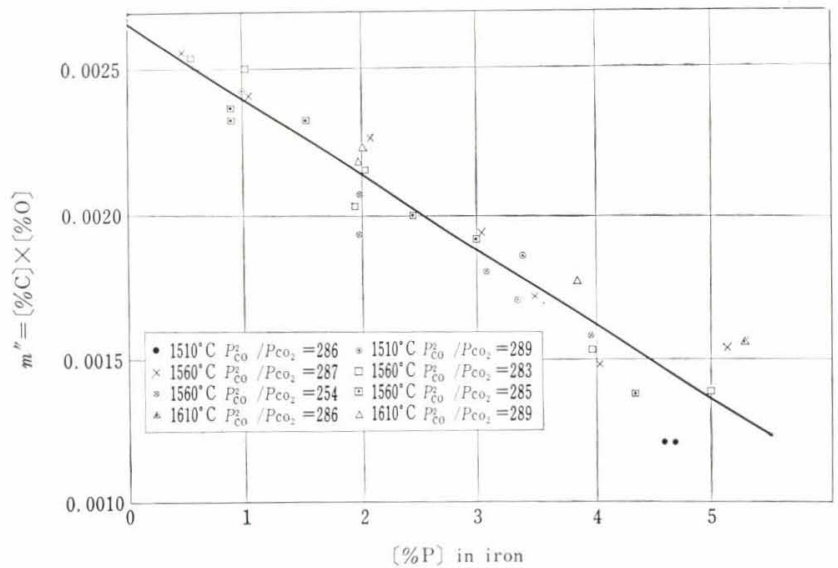

Fig. 5. Effect of phosphorus on carbon and oxgen product in iron 
change in the initial and final phosphorus content state was less than $0.15-0.2 \%$ of the phosphorus even for a very long melting time. So an attainment of equilibrium was checked by the change in the initial and final content of phosphorus in iron after 4 hr. of melting at a constant temperature.

At the end of the run, two samples were taken to determine the equilibrium composition in iron by withdrawing the melt with a silica tube, and were analized for phosphorus and carbon but not for oxygen. Because a sound ingot without a blowhole to analyze the oxygen content in iron was not obtained owing to gas evolution from melt during solidification, the killing method to fasten oxygen in liquid iron was conducted by adding a small amount of metallic aluminium to the iron. It could not be adopted because of a rapid reduction of phosphorus to metal from the crucible.

i. Equilibrium Relation of $\mathrm{CO}-\mathrm{CO}_{2}$ Gas Mixture and Phosphorus in Iron

Equilibrium equation of $\mathrm{CO}-\mathrm{CO}_{2}$ gas mixture with phosphorus in iron, in contact with solid $\mathrm{CaO}-4 \mathrm{CaO}$. $\mathrm{P}_{2} \mathrm{O}_{5}$ and its equilibrium constant is shown by the following equation:

$$
\begin{array}{r}
2 \underline{\mathrm{P}}+5 \mathrm{CO}_{2}+4 \mathrm{CaO}(\mathrm{S})=5 \mathrm{CO}+\mathrm{Ca}_{4} \mathrm{P}_{2} \mathrm{O}_{9}(\mathrm{~S}) \\
K_{4}=P_{\mathrm{CO}}^{5} / P_{\mathrm{CO}_{2}}^{5} \cdot a_{\mathrm{P}}^{2} \quad \ldots \ldots \ldots \ldots \ldots \ldots \ldots \ldots \ldots \ldots \ldots \ldots \ldots \ldots
\end{array}
$$

Fig. 6 records the data of corresponding $\log [\% \mathrm{P}]$ against $\log P_{\mathrm{CO}_{2}} / P_{\mathrm{CO}}$ at three different temperatures, in which three or four runs under the same experimental conditions are classified into one group. It is observed that each data at a constant temperature possesses a slope of about -2/5 except for two groups of the lowest phosphorus content at $1,560^{\circ}$ and $1,585^{\circ} \mathrm{C}$, because of Henry's law within the experimental error. The positive deviation from the slope of the two groups at the lowest phosphorus content may be caused by

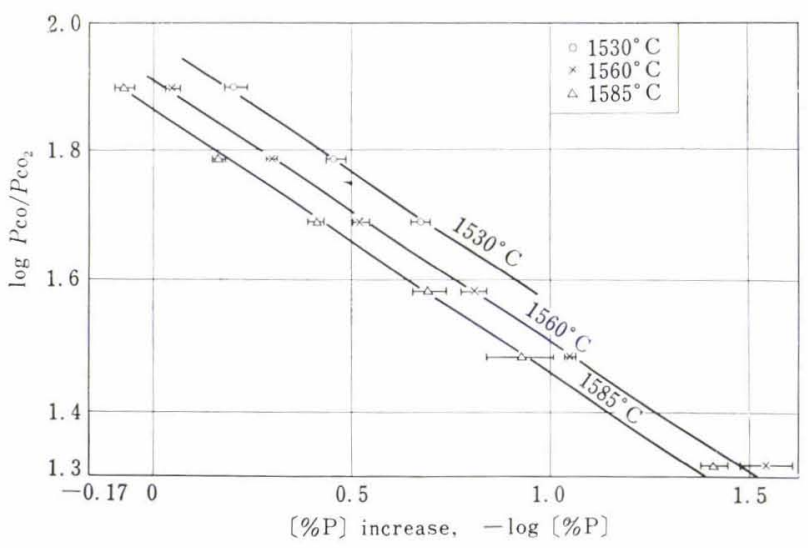

Fig. 6. Relation between $\mathrm{CO}-\mathrm{CO}_{2}$ gas mixture and phosphorus in liquid iron at $1,530^{\circ} \mathrm{C}, 1,560^{\circ} \mathrm{C}$ and $1,585^{\circ} \mathrm{C}$ the effect of oxygen on the activity of phosphorus in iron, because the two groups were carried out under a higher oxygen potential than the others. Therefore, it is also expected from these results that an interaction force between phosphorus and oxygen in iron is of a positive value. As mentioned above, since the mass action's law is established in this experiment with phosphorus, the activity of phosphorus in iron can be taken as equal to its weight percent when pure iron is used as the standard state. In Fig. 7, observed equilibrium constants of equation (4) are plotted against the reciprocal of the absolute temperatures and the results obtained are shown by the following equations :

$$
\begin{aligned}
\log K_{4}( & \left.=P_{\mathrm{CO}}^{5} / P_{\mathrm{CO}_{2}}^{5} \cdot a_{\mathrm{P}}^{2}\right)=32,070 / T-7.960 \\
J F_{4}^{\circ} & =-146,700+36.42 T \quad \ldots \ldots \ldots \ldots \ldots \ldots \ldots
\end{aligned}
$$

Thus, it has been recognized that elimination of phosphorus is favored by a higher oxygen potential and a lower temperature.

ii. Equilibrium Relation of Phosphorus and Carbon in Iron

The equilibrium relation of phosphorus and carbon in iron in the presence of solid $\mathrm{CaO}-4 \mathrm{CaO} \cdot \mathrm{P}_{2} \mathrm{O}_{5}$ is shown by the following equations:

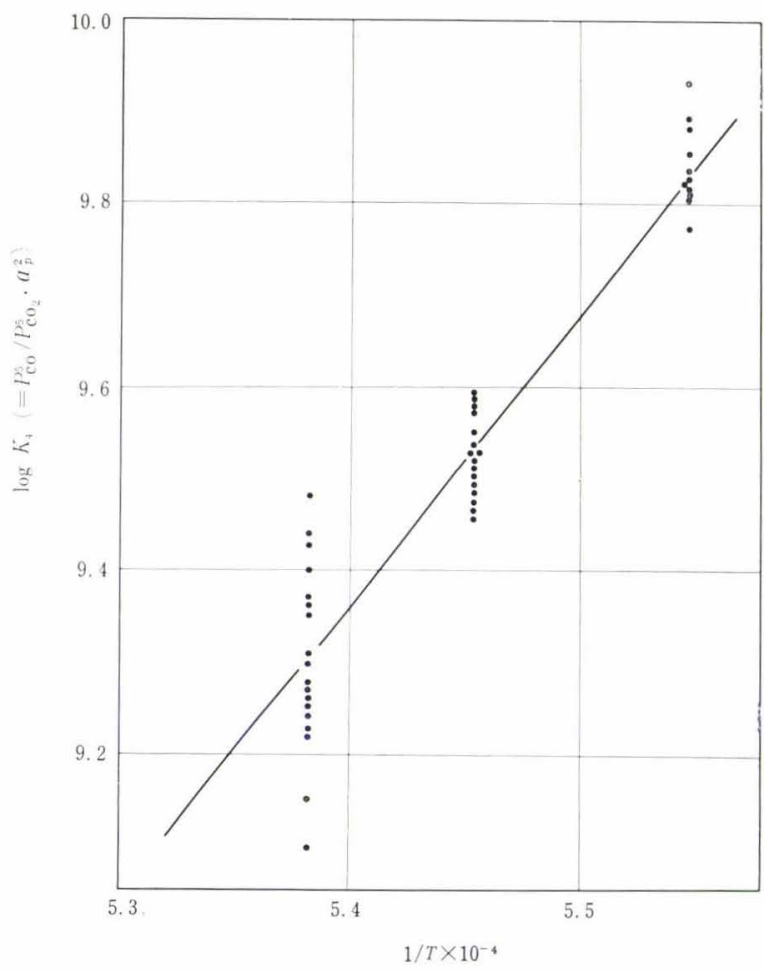

Fig. 7. Relation between $\log K_{4}$ and $1 / T$ 


$$
\begin{aligned}
& 2 \underline{\mathrm{P}}+5 \mathrm{CO}+4 \mathrm{CaO}(\mathrm{S})=5 \underline{\mathrm{C}}+\mathrm{Ca}_{4} \mathrm{P}_{2} \mathrm{O}_{9}(\mathrm{~S}) \\
& K_{5}=a_{\mathrm{C}}^{5} / a_{\mathrm{P}}^{2} \cdot P_{\mathrm{CO}}^{5}
\end{aligned}
$$

If the equilibrium relation shown by equation (5) was established, the activity of carbon in iron in equilibrium with $\mathrm{CO}-\mathrm{CO}_{2}$ gas mixture is governed by equation (1), $\underline{\mathrm{C}}+\mathrm{CO}_{2}=2 \mathrm{CO}$. In this experiment the relation of the carbon content in iron with $\mathrm{CO}$ $\mathrm{CO}_{2}$ gas mixture in the low phosphorus content range is in good agreement with the data of the pure Fe- $-\underline{-}-\underline{O}$ system obtained by the previous report ${ }^{6)}$. Therefore, by combining the value of equation (4b) with the data of the Fe- $\mathrm{C}-\mathrm{O}$ system obtained from the previous report ${ }^{6)}$, the equilibrium constant and the standard free energy change of equation (5) are deduced as follows:

$$
\begin{aligned}
\log K_{5}( & \left.=a_{\mathrm{C}}^{5} / a_{\mathrm{P}}^{2} \cdot P_{\mathrm{CO}}^{5}\right)=69,860 / T-41.79 \\
\Delta F_{5}^{\circ} & =-319,600+191.2 T \quad \ldots \ldots \ldots \ldots \ldots
\end{aligned}
$$

Fig. 8 shows the relation of the corresponding phosphorus content against the carbon concentration in iron at each experimental temperature, and the dotted lines are the values calculated by equation (5b). As shown in Fig. 8, the plotted experimental results are in good agreement with the dotted lines in the low phosphorus content range in iron but gradually deviate to low carbon values with an increasing phosphorus concentration in iron. The decline is more noticeable at a lower temperature. A reason for the deviation from Henry's law is explained by the interaction force between carbon and phosphorus in iron. The actual lines in Fig. 8, which are calculated by adding the effect of phosphorus on the activity coefficient of carbon in iron to the values of equation (5b) are in good agreement with the plotted experimental results.

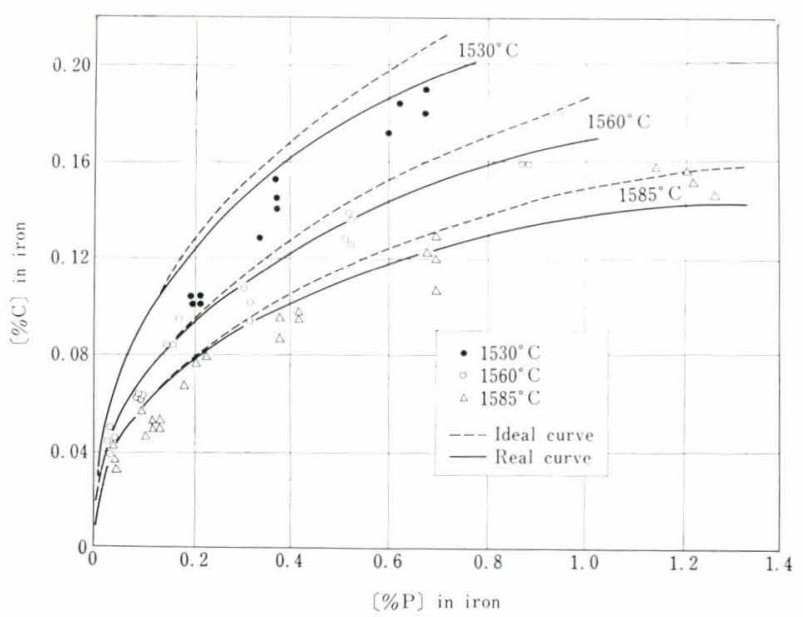

Fig. 8. Relation between carbon and phosphorus in iron
Thus, it has been found that refining at a lower temperature is more favorable in order to effectively eliminate the phosphorus in iron, anticipating a decarbonization in the steelmaking reaction.

iii. Equilibrium Relation of Phosphorus and Oxygen in Iron

Equilibrium relation of phosphorus and oxygen in iron in the presence of solid $\mathrm{CaO}-4 \mathrm{CaO} \cdot \mathrm{P}_{2} \mathrm{O}_{5}$ is shown by the following equation:

$$
\begin{array}{r}
2 \underline{\mathrm{P}}+5 \underline{\mathrm{O}}+4 \mathrm{CaO}(\mathrm{S})=\mathrm{Ca}_{4} \mathrm{P}_{2} \mathrm{O}_{9}(\mathrm{~S}) \\
K_{3}=1 / a_{\mathrm{P}}^{2} \cdot a_{0}^{5} \ldots \ldots \ldots \ldots \ldots \ldots \ldots \ldots \ldots \ldots \ldots \ldots \ldots \ldots
\end{array}
$$

In these series of measurements, the oxygen analysis of the final melt in equilibrium was not carried out because the sound ingot for determining the oxygen content in iron was unavailable. However, as mentioned above, by combining the value of equation (4b) with the data ${ }^{6}$ for the equilibrium relation of $\mathrm{CO}-\mathrm{CO}_{2}$ gas mixture with oxygen in iron, the following results are obtained.

$$
\begin{aligned}
\log K_{6}( & \left.=1 / a_{\mathrm{P}}^{2} \cdot a_{0}^{5}\right)=75,660 / T-31.77 . \\
\Delta F_{6}^{\circ} & =-136,100+145.3 T \quad \ldots \ldots \ldots \ldots . . .
\end{aligned}
$$

Fig. 9 shows the equilibrium relation of the oxygen content against the phosphorus content in iron at each temperature, and, at the same time, equilibrium relation of carbon and oxygen ${ }^{6}$ ) in the Fe- $-\underline{C}$ - system is also shown by a comparison of the deoxidizing power of phosphorus with that of carbon in iron. Thus it was found that the deoxidizing power of phosphorus in iron in the presence of solid $\mathrm{CaO}-4 \mathrm{CaO} \cdot \mathrm{P}_{2} \mathrm{O}_{5}$ was acceptable for the carbon at the steelmaking temperature. Especially, since the temperature depend-

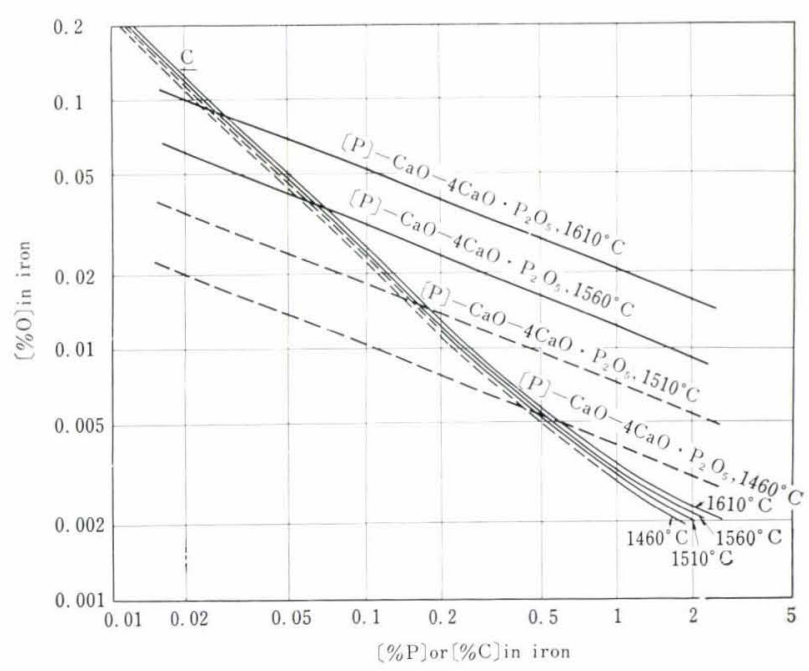

Fig. 9. Deoxidizing power of phosphorus and carbon in iron 
ence of the phosphorus-elimination reaction is greater than that of the carbon-oxygen reaction, it is interesting to note that the deoxidizing power of phosphorus at a lower temperature is stronger than that of carbon in iron.

Next, a comparison of the equilibium constant and the standard free energy change of equation (6b) and (6c) obtained by present work and by F. D. Richardson \& A. J. E. Welch ${ }^{4}$, who studied the equilibium relation of phosphorus in iron with hydrogen-water gas mixture, shows surprizingly good agreement as illustrated in Table 1 .

\section{Acknowledgments}

The authors wish to thank Prof. T. Fuwa for his

Table 1. Standard free-energy change and equilibrium constant for the reaction (6), $2 \mathrm{P}+5 \mathrm{O}+4 \mathrm{CaO}(\mathrm{S})=\mathrm{Ca}_{4} \mathrm{P}_{2} \mathrm{O}_{9}(\mathrm{~S})$

\begin{tabular}{|c|c|c|c|c|}
\hline \multirow{2}{*}{$\begin{array}{l}\text { Investigators } \rightarrow \\
\text { Temp. }\left({ }^{\circ} \mathrm{C}\right) \downarrow\end{array}$} & \multicolumn{2}{|c|}{ Ban-ya, Matoba } & \multicolumn{2}{|c|}{$\begin{array}{c}\text { Bookey, Richardson, } \\
\text { Welch }\end{array}$} \\
\hline & $\Delta F_{6}^{\circ}$ & $\log K_{6}$ & $\Delta F_{6}^{\circ}$ & $\log K_{6}$ \\
\hline 1530 & $-84,100$ & 10.16 & $-86,900$ & 10.52 \\
\hline 1560 & $-79,800$ & 9.48 & $-82,600$ & 9.83 \\
\hline 1585 & $-76,100$ & 8.92 & $-78,900$ & 9.27 \\
\hline
\end{tabular}

valuable suggestion, Dr. K. Hirokawa for his assistance of X-ray analysis and H. Obata, S. Shiko and H. Yoshizumi for their assistance in carrying out the experiment.

\section{REFERENCES}

1) T. B. Winkler \& J. Chipman; Trans. Met. Soc., Amer. Inst. Min., Met. \& Pet. Eng., 167 (1945), 111.

2) P. Vajraguta, A. G. Duerrell \& K. Balajiva: J. Iron $\&^{\circ}$ Steel Inst., 153 (1946), 115; 155 (1957), 563; 158 (1948), 505.

3) W. A. Fisher \& H. Von Ende: Stahl u. Eisen, 72 (1952), 1398, 1946.

4) J. B. Bookey, F. D. Richardson \& A. J. E. Welch: J. Iron छ̊ Steel Inst., 171 (1952), 404.

5) G. Urbain: Rev. de Metall., Oct. (1959), 529.

6) S. Ban-ya \& S. Matoba: Tetsu-to-Hagané Overseas, 3 (1963), $1,21$.

7) M. A. Bredig, H. H. Frank \& F. Füldner: Zeitschrift $f$. Electrochemie, 38 (1932), 158.

8) C. Wagner: Thermodynamics of Alloys, Addison-Wesley, Cambridge, Mass. 1952.

9) J. Peason \& E. T. Turkdogan: J. Iron $\mathcal{G}^{\circ}$ Steel Inst., 176 (1952), 19

10) H. P. Levents \& A. M. Samarin: Doklady Akad. Nauk SSSR, 101 (1955), No. 6.

11) D. Dutilloy \& J. Chipman: Trans. Met. Soc., Amer. Inst. Min., Met. \& Pet. Eng., 218 (1960), 428.

12) K. Sambongi \& H. Koizumi: Tetsu-to-Hagané, 47 (1961), 1329. 